\title{
Estimation of Glomerular Filtration Rate: Which Formula to Apply in G-Spot Subjects Aged 1 - 17 Years?
}

\author{
Hamadoun Yattara1, Djibril Mamadou Couliblay², Nouhoum Coulibaly' ${ }^{*}$, Pamela Samiza1, \\ Seydou Sy1, Arboncana Maiga², Djeneba Diallo', Moustapha Tanagra1, Alkaya Touré1, \\ Magara Samaké3, Niagalé Diakité ${ }^{3}$, Aboubacar Sidiki Fofana ${ }^{3}$, Ibrahim Izetiengou Maiga², \\ Sahare Fongoro ${ }^{1}$
}

\footnotetext{
${ }^{1}$ Nephrology and Hemodialysis Department of the Point G University Hospital, Bamako, Mali

${ }^{2}$ Medical biology Laboratory Service of the Point G University Hospital, Bamako, Mali

${ }^{3}$ Nephrology Department of the Regional Hospital of Kayes, Kayes, Mali

Email: *nouhcoulibaly14@gmail.com
}

How to cite this paper: Yattara, H., Couliblay, D.M., Coulibaly, N., Samiza, P., Sy, S., Maiga, A., Diallo, D., Tanagra, M., Touré, A., Samaké, M., Diakité, N., Fofana, A.S., Maiga, I.I. and Fongoro, S. (2021) Estimation of Glomerular Filtration Rate: Which Formula to Apply in G-Spot Subjects Aged 1 - 17 Years? Open Journal of Nephrology, $11,397-402$.

https://doi.org/10.4236/ojneph.2021.113032

Received: July 27, 2021

Accepted: August 28, 2021

Published: August 31, 2021

Copyright $\odot 2021$ by author(s) and Scientific Research Publishing Inc. This work is licensed under the Creative Commons Attribution International License (CC BY 4.0).

http://creativecommons.org/licenses/by/4.0/

(c) (i) Open Access

\begin{abstract}
Introduction: Morbidity and mortality in paediatric practice is dominated in Africa by malaria, diarrhoeal diseases and acute respiratory infections. Aim: In order to evaluate the Glomerular Filtration Rate (GFR) with the formulas commonly used by medical laboratories, we proposed to undertake this study. Patients and Method: This was a descriptive, prospective and cross-sectional study conducted at the PA and KA medical biology laboratory in Bamako Hamdalaye ACI 2000 in collaboration with the medical biology and hospital hygiene laboratory service at the Point G University Hospital. Results: During the study period, we recruited 360 subjects, 189 of whom were male $(52.5 \%)$ and 171 female (47.5\%). The mean age was $8.75 \pm 4.8$ years with extremes of 1 and 17 years. Subjects aged 15 to 17 years were the most numerous. The reference means GFR of the subjects according to age was with the SCHWARTZ formula $179.16 \pm 50.47$ with extremes of 173.93 and 184.39 ; with CKD-Epi $37.63 \pm 11.25$ with extremes of 36.46 and 38.79 ; with MAYO $107.87 \pm 18.11$ with extremes of 105.99 and 109.75 and MDRD $350.83 \pm 251.15$ with extremes of 324.79 and 376.86. Conclusion: The Mayo formula showed a better distribution around the mean than other formulas for estimating the glomerular filtration rate.
\end{abstract}

\section{Keywords}

Glomerular Filtration Rate, Reference Value, Young Subjects 


\section{Introduction}

Morbidity and mortality in pediatric practice are dominated in Africa by malaria, diarrhoeal diseases and acute respiratory infections [1]. The share of uronephrology pathology is likely to be secondary to childhood morbidity and mortality worldwide [2]. In developed countries, urinary tract infections, hereditary diseases and malformative uropathies are the most common renal diseases in children [3]. Renal disease is characterised by the predominance of acquired nephropathies, particularly glomerular nephropathies in developing countries [4]. Kidney disease is a growing concern worldwide, in both adults and children, but its extent and distribution differ between developed and tropical countries [2]. The diagnosis of renal failure is based on the estimation of Glomerular Filtration Rate (GFR). This is the value that quantifies the activity of the kidney. It is classically estimated by serum and urine creatinine, which requires the collection of 24-hour urine. In Mali, work on renal pathologies in children is rare. In order to evaluate GFR with the formulas commonly used by medical laboratories, we proposed to undertake this study. The objective was to study the reference values of creatininemia and to estimate the glomerular filtration rate of subjects aged 1 to 17 years in the laboratory of medical biology and hospital hygiene of the University Hospital Centre (CHU) of Point-G.

\section{Materials and Methods}

This was a descriptive, prospective, cross-sectional study conducted at the PA and KA medical biology laboratory in Bamako Hamdalaye ACI 2000 in collaboration with the medical biology and hospital hygiene laboratory service at the Point G University Hospital. The study population consisted of children of both sexes, whose age ranged from 1 to 17 years, who came to the laboratory for blood tests. Creatinine, age, height and sex were the parameters explored to assess renal function, particularly glomerular function. The enzymatic method was used for the quantification of creatinine in the subjects.

The inclusion criteria were: subjects of both sexes with ages ranging from 01 to 17 years, recruited consecutively at the PA and KA medical biology laboratory.

The non-inclusion criteria concerned subjects aged 18 years and over; children whose creatinine was not requested in the blood test.

Data were entered into Microsoft World Office 2016, Microsoft Excel 2016 and analysed with SPSS.21 software. The ANOVA test was used for comparison of proportions.

Results: During the study period, we recruited 360 subjects, 189 of whom were male (52.5\%) and 171 female (47.5\%). The mean age was $8.75 \pm 4.8$ years with extremes of 1 and 17 years. Subjects aged 15 to 17 years were the most numerous. The main formulas used to estimate glomerular filtration rate were: SCHWARTZ formula, CKD-Epi formula, MDRD formula and MAYO quadratic formula.

Creatinine clearance was greater than or equal to $90 \mathrm{ml} / \mathrm{min}$ according to the SCHWARTZ formula in most of our patients (Table 1). Subjects with a GFR greater than or equal to $90 \mathrm{ml} / \mathrm{min}$ according to the CKD-EPI formula were rare (Table 2). 
Table 1. Distribution of 360 subjects according to creatinine and glomerular filtration rate with the SCHWARTZ formula.

\begin{tabular}{cccccc}
\hline $\begin{array}{c}\text { Creatinine values } \\
(\mu \mathrm{mol} / \mathrm{l})\end{array}$ & \multicolumn{2}{c}{ GFR according to the Schwartz formula $(\mathrm{ml} / \mathrm{min})$} & \multirow{2}{*}{ Total } \\
\cline { 2 - 4 } & $15-29$ & $30-59$ & $60-89$ & $\geq 90$ & \\
\hline$<15$ & 0 & 0 & 0 & 5 & 5 \\
{$[15-31]$} & 0 & 0 & 0 & 85 & 85 \\
$>31$ & 3 & 3 & 4 & 260 & 270 \\
Total & 3 & 3 & 4 & 350 & 360 \\
\hline
\end{tabular}

Of 350 subjects, 85 (24.3\%) had normal creatinine levels with normal or increased GFR.

Table 2. Distribution of 360 subjects according to creatinine and glomerular filtration rate with the CKD-Epi formula.

\begin{tabular}{cccccc}
\hline $\begin{array}{c}\text { Creatinine values } \\
(\mu \mathrm{mol} / \mathrm{l})\end{array}$ & \multicolumn{2}{l}{ GFR according to the CKD-Epi formula $(\mathrm{ml} / \mathrm{min})$} & Total \\
\cline { 2 - 5 } & $<15$ & $15-29$ & $30-59$ & $60-89$ & \\
\hline$<15$ & 0 & 0 & 1 & 3 & 4 \\
{$[15-31]$} & 0 & 0 & 85 & 0 & 271 \\
$>31$ & 18 & 22 & 231 & 0 & 360 \\
\hline
\end{tabular}

No subject had normal creatinine levels with normal or increased GFR.

According to the MDRD formula, almost all of our subjects had a GFR greater than or equal to $90 \mathrm{ml} / \mathrm{min}$, while the majority of subjects had a GFR greater than or equal to $90 \mathrm{ml} / \mathrm{min}$ according to the MAYO formula. The mean reference GFR of the subjects according to age was with the SCHWARTZ formula $179.16 \pm$ 50.47 with extremes of 173.93 and 184.39 ; with CKD-Epi $37.63 \pm 11.25$ with extremes of 36.46 and 38.79; with MAYO $107.87 \pm 18.11$ with extremes of 105.99 and 109.75 (Table 3) and MDRD $350.83 \pm 251.15$ with extremes 324.79 and 376.86 .

In our study, the mean found in boys was $180.34 \pm 49.25$ for DFG SCHWARTZ; $38.00 \pm 11.49$ for CKD-Epi; $109.12 \pm 18.12$ for DFG MAYO and $414.41 \pm 270.61$ for DFG MDRD while in girls the mean found was $177.86 \pm 51.90$ for DFG SCHWARTZ; $37.21 \pm 10.99$ for CKD-Epi; $106.48 \pm 18.05$ for DFG MAYO and $280.55 \pm 206.77$ for DFG MDRD.

\section{Comments and Discussion}

The study is the first of its kind conducted in Mali. It was carried out with recruitment of subjects of both sexes without distinction. The methodological choice of this study constitutes the main bias since there was no case control. The recruitment concerned only black African subjects for whom the socio-demographic and clinical characteristics were not evaluated. It does not allow us to generalise our results to the whole population. However, this work allows us to determine the best formula for estimating GFR in our context. 
Table 3. MAYO GFR reference values of subjects according to age.

\begin{tabular}{ccccccc}
\hline & \multicolumn{5}{c}{ GFR according to the MAYO formula } \\
\cline { 2 - 7 } Age (ans) & Size & Average \pm ET & Lower bound & Upper bound & Minimum & Maximum \\
\hline$[1-3]$ & 24 & $116.66 \pm 6.61$ & 113.87 & 119.45 & 99.80 & 123.40 \\
{$[3-5]$} & 39 & $109.89 \pm 15.68$ & 104.80 & 114.97 & 44.14 & 124.28 \\
{$[5-7]$} & 31 & $109.58 \pm 22.54$ & 101.31 & 117.85 & 6.18 & 123.62 \\
{$[7-9]$} & 40 & $106.92 \pm 18.12$ & 101.13 & 112.72 & 29.51 & 125.98 \\
{$[9-11]$} & 41 & $113.19 \pm 10.66$ & 109.83 & 116.56 & 85.26 & 127.22 \\
{$[11-13]$} & 43 & $112.31 \pm 12.45$ & 108.48 & 116.15 & 73.38 & 127.32 \\
{$[13-15]$} & 48 & $102.97 \pm 27.67$ & 94.93 & 111.00 & 0.54 & 128.40 \\
{$[15-17]$} & 94 & $102.77 \pm 16.24$ & 99.45 & 106.10 & 33.17 & 127.92 \\
Total & 360 & $107.87 \pm 18.11$ & 105.99 & 109.75 & 0.54 & 128.40 \\
\hline
\end{tabular}

ANOVA test; $\mathrm{ddl}=352 ; \mathrm{p}=0.026$. The mean MAYO GFR was $107.87 \pm 18.11$ with extremes of 105.99 and 109.75 according to age.

In our study, male gender was slightly dominant (52.5\%), mean age was $8.75 \pm$ 4.80 years and subjects aged $15-17$ years were the most numerous (26.1\%). This same male predominance was found in a study conducted in Morocco in 2012 and a mean of $9.7 \pm 4.7$ with extremes of 8 months and 16 years [4]. Most patients had normal or lower creatinine levels than the reference values. These same reference values with extremes of $15-104 \mu \mathrm{mol} / \mathrm{L}$ were found according to age in our study.

Glomerular filtration rate was $\geq 90 \mathrm{ml} / \mathrm{min}$ with the SHWARTZ formula; $84.36 \%$ (329/360) with the MAYO quadratic formula, 97.77\% (352/360) with the MDRD formula in more than $97.22 \%$ (350/360) of our subjects depending on age. These results are comparable to those of Bourrilon in 2008 in France [5] and Garba et al in 2018 in Niger [6], who respectively found GFR values ranging from $133 \pm 27$ to $140 \pm 30 \mathrm{ml} / \mathrm{min} / 1.73 \mathrm{~m}^{2}$ and $201.04 \mathrm{ml} / \mathrm{min} / 1.73 \mathrm{~m}^{2}$ in subjects aged 2 to 21 years.

This difference in the direction of increase could be explained by the methodology used. Our patients had no specific pathology with an age limit of 17 years.

Out of 350 subjects, $24.3 \%$ had normal creatinine levels with normal or increased GFR using the SHWARTZ formula. This result is close to those obtained with the MAYO GFR formula and the MDRD GFR formula: they were $25.53 \%$ in 329 subjects and $24.15 \%$ in 352 subjects respectively.

Of 352 subjects, $24.15 \%$ had normal creatinine levels with normal or increased GFR using the MDRD formula. This result differs from the CKD-Epi formula which had no normal or increased GFR. According to the High Authority for Health report in 2011 [7], the CKD-Epi formula has similar accuracy but is more accurate than the MDRD formula at GFR values above $60 \mathrm{ml} / \mathrm{min} / 1.73 \mathrm{~m}^{2}$. This is in contradiction with our results. This difference with the literature may be explained by a difference in the methodology used as our recruited subjects were 
not sick children.

We noted a significant difference between CKD-Epi $\left(\mathrm{p}<10^{-6}\right)$ and MDRD ( $\mathrm{p}$ $\left.<10^{-6}\right)$ GFR. There was no significant difference between SCHWARTZ $(\mathrm{p}=0.346)$ and MAYO ( $p=0.026)$ GFRs. From these results, we see a good distribution of the SCHWARTZ GFR and MAYO GFR. The MAYO GFR shows a better distribution in our study population compared to other glomerular filtration rate estimation formulas. Although the Schwartz formula is the most commonly used formula in children according to the literature, our study provided results that allowed us to rank it second to the MAYO formula. No similar studies were found that addressed the issue in the same way.

The mean found in boys was $180.34 \pm 49.25$ for DFG SCHWARTZ; $38.00 \pm 11.49$ for CKD-Epi; $109.12 \pm 18.12$ for DFG MAYO and $414.41 \pm 270.61$ for DFG MDRD. It was $177.86 \pm 51.90$ for DFG SCHWARTZ; $37.21 \pm 10.99$ for CKD-Epi; $106.48 \pm$ 18.05 for DFG MAYO and $280.55 \pm 206.77$ for DFG MDRD in girls.

These results are comparable to those found by Legrain in Paris in 2015 which were $72 \pm 57$ for GFR MDRD and $61 \pm 24$ for GFR CKD-Epi in males and $69 \pm$ 27 for MDRD and $63 \pm 20$ for CKD-Epi in females [8]. This difference may be explained by the age difference in our study population.

\section{Conclusion}

Our study allowed us to estimate the GFR of 360 subjects aged 1 to 17 years at Point G University Hospital. The formulas used in our study were: the SCHWARTZ formula, the MDRD formula, the CKD-Epi formula and the MAYO quadratic formula. The Mayo formula showed a better distribution around the mean than the other formulas for estimating glomerular filtration rate in black Africans.

\section{Conflicts of Interest}

The authors declare no conflicts of interest regarding the publication of this paper.

\section{References}

[1] Diarra, Y., Combary, A., Ouédraogo-Traoré, R., et al. (2003) Interest of Reactive Strips in the Screening of Urinary Tract Infections in African Pediatric Settings. Cahiers Santé, 13, 121-123.

[2] Cochat, P., Mourani, C., Exantus, J., Bourquia, A., Martinez-Pico, M., Adonis-Koffy, L. and Bacchetta, J. (2009) Pediatric Nephrology in Developing Countries. Tropical Medicine, 69, 543-547.

[3] Sawadogo, N.I. (1967) Study of the Epidemiological and Clinical Aspects of the Main Ocular Complications during Diabetes Mellitus at the Yalgado Ouédraogo National Hospital [Thesis]. University of Ouagadougou, Ouagadougou.

[4] El Omairi, N. (2012) Insuffisance rénale chronique chez l'enfant [Thesis]. Sidi Mohammed Ben Abdellah University of Fez, Fez.

[5] Bourrilon, A. (2008) Pediatric Emergencies. Pediatrics, 5th Edition, Elsevier-Masson, Paris.

[6] Garba, M., Tondi, Z.M., Diongoule, H., Aboubacar, S., Ide, A., Biyao-Nelson, N.R., Sou- 
maila, I. and Alido, S. (2018) Screening for Nephropathy in Major Sickle Cell Syndromes in Patients Followed at the National Reference Centre for Sickle Cell Disease in Niamey, Niger. Nephrology \& Therapeutics, 14, 462-466.

https://doi.org/10.1016/j.nephro.2017.11.002

[7] Haute Autorité de Santé (2011) Evaluation of Glomerular Filtration Rate and Creatinine Measurement in the Diagnosis of Chronic Kidney Disease in Adults. Biotribune Magazine, 41, 6-9.

[8] Legrain, P.S. (2015) Evaluation of Renal Function in the Elderly according to the CG, MDRD, CKD-EPI Formulas and Its Impact on Drug Prescriptions [Thesis]. University of Paris Diderot, Paris. 